\title{
Editorial
}

\section{¿Comisión para el desarrollo nacional?}

El señor Presidente es un especialista en hacer propuestas sorpresivas y sorprendentes; asf hemos recibido el anuncio de la conformación de una Comisión para el Desarrollo Nacional, en alocución dirigida a la nación en vísperas del $1^{\circ}$ de mayo. En primer lugar, no queda muy claro el origen motivador de este "mandato de concertación". Se puede leer así el resultado de las recientes elecciones que han mermado el monopolio o efecto-dominación del partido oficial en la Asamblea Legislativa. Por concertación parece que se ha procedido a la elección de la nueva directiva del poder legislativo. Votantes y no votantes han patentizado su desacuerdo ante la falta de rumbo nacional; a través del voto legislativo han enviado su mensaje al poder ejecutivo.

También el origen motivador del mandato de concertación ha podido llegar primordialmente del "proyecto o plan de nación" recomendado al gobierno por el Banco Mundial. Aparte del verdadero origen motivador, lo sorpresivo es que inesperadamente se proponga la formulación de un Plan de Desarmollo Nacional, sin que la breve alocución detalle los cuatro términos: formulación, plan, desarrollo y nacional. Es sorpresivo porque se trata de un gobierno que se inicia con la supresión del Ministerio de Planificación y Coordinación del Desarrollo Económico y Social. Un contínuo interrogante en estos tres años de gobierno ha sido la existencia de un plan desarrollo; si existe se debe publicar y conocer, porque si no se publica, ni es plan, ni es nacional, ni sirve al desarrollo.

Esto es lo que explícitamente reconoce el señor Presidente:"la formulación de un Plan de Desarrollo Nacional, con una visión de mediano y largo plazo, que nos lleve al desarrollo y genere estabilidad y confianza, y que sea impulsado por los gobiernos que alternativamente ejerzan el poder en el futuro". Esta frase 
dice más de lo que dice. Dice que no tenemos un plan de desarrollo nacional, lo cual sospechábamos a juzgar por la serie de medidas novedosas anunciadas en los tres pasados años: dolarización, IVA, maquilas, aranceles, privatización, clusters..., más documentos confidenciales con el FMI que comprometían buena parte de la privatización de ANTEL para el pago de los $\$ 150$ millones de LETES. Dice que carecemos de una visión de mediano y largo plazo, que nos lleve al desarrollo, es decir que no hay desarrollo sin un plan de desarrollo. Dice además que la estabilidad y la confianza pueden lograrse si existe un plan de desarrollo. Y recomienda a los gobiernos futuros que impulsen un plan de desarrollo, porque no basta con editar Programas Monetario-Financieros, que año con año repiten similares consignas.

Como el tema de la falta de rumbo económico rebotaba de diario en diario, debido sobre todo a la seria recesión surgida desde 1995, no es casualidad que diez días antes del discurso presidencial, con fecha de domingo 20 de abril-1997, el Ing. Edgardo Suárez, miembro del antiguo CONAPLAN y luego presidente del BCR, planteara un interrogante similar en un breve artículo: "Plan de Desarrollo ¿versus programa económico?" - Muy en resumen, el Ing. E.Suárez lamenta la decisión del presente gobierno de demoler ("con los cañones del Navarone") el Ministerio de Planificación y Coordinación del Desarrollo Económico y Social. El error de esta decisión está en la pérdida de una de una visión de futuro, "que daría orientación y realismo a los programas económicos y monetarios de corto plazo". En la actualidad, añade el Ing. E.Suárez, tengo la impresión de que nunca existió un Plan de Desarrollo Económico y Social, ni programas sectoriales, ni mucho menos un programa consolidado de inversiones públicas bianual, ajustable anualmente. Tal vez exista un "Programa Económico de Gobierno", mal vendido o poco publicitado, y en gran medida derivado de los Programas Monetarios anuales del BCR. Surge así la pregunta: i quién orienta al orientador?

Parecería que el actual gobierno ha dado muchos pasos hacia atrás con la supresión de esa institución analítica y orientadora del desarrollo nacional, que difícilmente se subsana con una espontánea "comisión" de personalidades distinguidas. No significa esto ningun reparo a las personas escogidas, porque esperamos que algun miembro de la comisión proponga como primer tema de agenda la reconstitución del Ministerio de Planificación. La alocución sigue siendo sorpresiva y sorprendente porque este gobierno ha sustituído la planeación económica por el "sigilo y el secreto", sumados a la improvisación, impuestos por una minoría privilegiada y autoelegida, que Héctor Dada califica como “¿dictadura del empresariado?".

Aunque un plan de desarrollo nacional abarca más áreas, problemas e interrogantes que un plan de desarrollo económico y social, manteniéndonos de momento en esta última esfera, conviene recordar que el año de 1996 fué prolífero en la presentación de propuestas económicas, abiertas al diálogo o concertación 
(ANEP, FUNDE, FMNL, CPDN, FUSADES...), porque se tenfa la sensación generalizada de que El Salvador no tenfa un rumbo orientador, de parte del gobiemo, mientras que la economfa real se venfa enrumbando hacia una grave terciarización económica, hacia un predominio del capital especulativo y hacia una reconcentración de la riqueza nacional. Estos documentos hablaban de un crecimiento ficticio, frágil y no sostenible, enfatizaban el riesgo del deterioro del medio ambiente y criticaban la precipitación y la falta de transparencia legal en el proceso de las privatizaciones. El gobiemo oy6, pero no escuchó.

Adicionalmente, el Comité Económico y el resto de unidades gubernamentales, no han mostrado la menor atención e interés ante la publicación de nuestras matrices intersectoriales de 1978, y sobre todo de 1990 (publicada en 1993), obra del Banco Central, que hubieran servido a la orientación del crédito hacia sectores realmente productivos y reproductivos. La propia ANEP ha venido criticando el sesgo en la orientación del crédito hacia áreas de mayores márgenes de ganancia en el corto plazo (comercio y servicios), sacrificando la inversión productiva en los sectores primario-secundario, que generan más valor agregado y capacidad exportadora. El oligopolio financiero obtiene ingentes beneficios, poco fiscalizados, mientras que el conjunto de las ramas productoras se ven sometidas a una gravosa recesión económica. Votantes y no votantes han expresado su parecer en las últimas elecciones.

El Instituto de Turismo, con beneplácito del gobierno, está editando, en inglés, unos lujosos y caros folletos, a modo de gura oficial para el visitante de El Salvador. Pero las fotos y los atrayentes comentarios no logran borrar de la memoria o conciencia de los residentes internos otros problemas cuantitativos y cualitativos, que también rebotan de diario en diario y de televisión a televisión, como son la inseguridad y crimen, organizado y desorganizado, la corrupción ampliada, el lavado de dólares y el lavado de cerebros, traducidos en gran insolidaridad social. Sin duda, los miembros de la "Comisión" se atreverán a listar algunos de estos temas en Casa Presidencial. Pero han sido tantas las "comisiones ad-hoc" sin mayores resultados prácticos, que confirman el dicho de que cuando no se tiene interés en que algo se haga, se nombra una comisión. 